\title{
PENGEMBANGAN INDIKATOR PENILAIAN KINERJA PENERAPAN FAKTOR LINGKUNGAN SUPPLY CHAIN UMKM
}

\author{
Sri Wahjuni Latifah ${ }^{1}$ \\ Dhaniel Syam ${ }^{1}$ \\ ${ }^{1}$ Fakultas Ekonomi dan Bisnis, Universitas Muhammadiyah Malang, Indonesia \\ 1yuni.latifah14@gmail.com
}

\begin{abstract}
This research is conducted with the aim of developing SMES performance assessment indicators by implementing the supply chain environmental factors so that it can be used to assess the performance of SMES not only financial based but to non Financial. Data is collected by sending queitioner and interviews to MSME managers, employees and consumers are obtained sixty SMES. The research variables are developed from the Balance Score Card concept and supply chain management. Data analysis techniques are done with qualitative descriptive. And then the analysis of factors to determine the indicator in the determination of SMES performance. The results showed that there are four factors that can be used to determine the SME performance indicators: resource factors, financial factors, customer factors and the SCM (Supply Chain Management) factor.
\end{abstract}

Keywords: performance indicators, SMES, supply chain environment

\section{PENDAHULUAN}

Sebuah usaha didirikan dengan berbagai tujuan, tujuan jangka pendek maupun tujuan jangka panjang. Tujuan jangka pendek lebih difokuskan pada pencapaian laba, sedangkan tujuan jangka panjang lebih dari sekedar pencapaian laba yaitu untuk keberlangsungan usaha. Untuk itu menilai kinerja perusahaan menjadi sebuah keputusan penting bagi para manajer. Penilaian kinerja perlu dilakukan secara periodik untuk mengetahui apakah dalam satu periode usaha tersebut telah mencapai tujuan atau belum dan apakah usaha tersebut lebih baik dibanding perusahaan lain. Dengan penilaian kinerja maka manajer dapat melakukan perbaikan untuk mencapai tujuan yang telah ditetapkan.

Penilaian kinerja dapat dilakukan dengan berbagai pendekatan baik pendekatan financial maupun non financial. Pendekatan financial mengukur kinerja perusahaan dari aspek keuangan menggunakan rasio keuangan seperti rasio profitabilitas, rasio likuiditas, rasio solvabilitas dan rasio aktivitas. Sedangkan pengukuran kinerja berdasar non financial seperti yang dikenal dalam Balance score card yaitu pengukuran kinerja dengan indikator keuangan, pelanggan, proses bisnis internal, pertumbuhan dan pembelajaran.

Perusahaan dapat menentukan berbagai indikator penentuan kinerja yang sesuai dengan karakteristik 
perusahaannya. Hal ini karena perusahaan dapat menentukan pengukuran kinerja sesuai dengan kepentingannya. Dalam hal ini kepentingan eksternal maupun kepentingan internal. Kepentingan eksternal berkaitan dengan keputusan kredit, investasi atau keputusan perpajakan. Sedangkan keputusan internal lebih berkaitan dengan evaluasi kinerja perusahaan untuk memperoleh informasi penting tentang value added proses bisnisnya. Indikator kinerja internal dapat berupa peningkatan kompetensi dan komitmen personel, peningkatan produktivitas dan cost effectiveness dan komitmen pelanggan(Zaroni, 2018).

\section{Demikian juga Usaha Mikro}

Kecil dan Menengah(UMKM) yang merupakan salah satu kekuatan ekonomi rakyat yang paling penting, maka perlu dikembangkan dari berbagai aspek, baik aspek legalitas, aspek manajemen maupun aspek lingkungan yang mempengaruhi untuk mencapai tujuan. Salah satu strategi untuk mencapai keberlanjutan UMKM adalah dengan memenuhi kebutuhan stockholders, karyawan serta pemenuhan faktor lingkungan. Seperti diketahui bahawa perusahaan terhubungdengan unsurunsur lingkungannya melalui aliran sumber daya lingkungan(environmental resources flow). Beberapa sumber daya mengalir lebih sering daripada sumber daya lain (Mcleod, \& Schell, 2008). Aliran-aliran yang umum terjadi meliputi aliran informasi dari customer, aliran barang kepada customer, aliran kepada pemegang saham, aliran bahan dari pemasok. Jalur yang memfasilitasi aliran sumber daya fisik dari pemasok kepada perusahaan dan selanjutnya kepada pelanggan disebut rantai pasokan(supply chain). Aliran sumber daya melalui rantai pasokan harus dikelola untuk memastikan bahwa aliran tersebut terjadi dengan cara yang tepat waktu dan efisien, proses ini dikenal manajemen rantai pasokan(supply chain management).

Disisi lain, Usaha Kecil Mikro dan Menengah(UMKM) dalam perekonomian nasional memiliki peran yang sangat penting dan strategis. Kondisi tersebut dapat dilihat dari berbagai data empiris yang mendukung bahwa eksistensi UMKM cukup dominan dalam perekonomian Indonesia. Industri kecil memiliki peranan cukup besar dalam sektor perekonomian di Indonesia dilihat dari jumlah unit usaha, daya serap terhadap tenaga kerja dan mendukung pendapatan rumah tangga. Penelitian tentang rantai pasokan pada UMKM Malang telah dilakukan oleh peneliti pada tahun 2018 . Berdasarkan hasil pengujian terhadap dimensi lingkungan rantai pasokan 
UMKM dapat ditemukan bahwa lingkungan internal yang terdiri dari inovasi, intelectual knowledge dan best practice tidak berpengaruh pada keunggulan bersaing UMKM. Sedangkan faktor lingkungan eksternal yang meliputi persaingan tradisional, pendatang baru dan produk pengganti berpengaruh pada keunggulan bersaing UMKM seperti temuan Latifah \& Yuliati ( 2019).

Pengukuran kinerja yang menyeimbangkan aspek keuangan dan non keuangan dikenal dengan Balance Score Card(BSC). BSC dikembangkan oleh Dr. Robert Kaplan dan David Norton pada tahun 1990. BSC merupakan salah satu metode untuk menerapkan strategi bisnis sebuah perusahaan yang terbukti dapat mencapai tujuan perusahaan. BSC memiliki keunggulan dari pada pengukuran kinerja konvensional karena mengukur kinerja perusahaan dengan empat perspektif yaitu: keuangan, pelanggan, Proses Bisnis internal, pembelajaran dan pertumbuhan. Pendekatan pengukuran kinerja dengan model BSC belum tentu dapat digunakan untuk UMKM, mengingat UMKM memiliki keunikan sendiri dan banyak keterbatasan dari aspek record data. Untuk itu penelitian ini dilakukan untuk mengembangkan indikator pengukuran kinerja berdasar faktor lingkungan Supply Chain Management UMKM. Dari uraian di atas maka rumusan masalah penelitian ini adalah: (1). Apakah faktor lingkungan internal yang terdiri dari perspektif keuangan, pelanggan, proses bisnis internal dan pertumbuhan pembelajaran dapat menjadi indikator yang sesuai untuk mengukur kinerja UMKM? Dan (2). Apakah faktor lingkungan eksternal yang terdiri dari Supply Chain Managemet dan Customer Relationship Management dapat menjadi indikator dalam menentukan kinerja UMKM?

Pengukuran kinerja yang menyeimbangkan aspek keuangan dan non keuangan dikenal dengan Balance Score Card(BSC). BSC dikembangkan oleh Dr. Robert Kaplan dan David Norton pada tahun 1990. BSC merupakan salah satu metode untuk menerapkan strategi bisnis sebuah perusahaan yang terbukti dapat mencapai tujuan perusahaan. BSC memiliki keunggulan dari pada pengukuran kinerja konvensional karena mengukur kinerja perusahaan dengan empat perspektif yaitu: keuangan, pelanggan, Proses Bisnis internal, pembelajaran dan pertumbuhan.

Berkaitan dengan rantai pasokan sebuah perusahaan tentunya berkaitan dengan bagaimana perusahaan mencapai tujuan dengan mendasarkan perspektif keuangan dan indikator non keuangan. 


\section{FAKULTAS EKONOMI DAN BISNIS UNIVERSITAS WIRARAJA - MADURA}

Dalam rantai pasokan sebuah perusahaan terhubung dengan lingkungan yang terdiri dari pemasok, pelanggan dan pihak eksternal lainnya seperti pemerintah. Hal ini dapat menjadi sebuah komponen dalam perspektif BSC yaitu perspektif keuangan, pelanggan, proses bisnis internal dan pertumbuhan pembelajaran.

\section{METODE PENELITIAN}

Ruang lingkup penelitian ini adalah UMKM di Kota Malang dan Kota Batu yang tergabung dalam Paguyuban UMKM dibawah bimbingan Departemen Koperasi dan UKM. Sesuai dengan tujuan penelitian dalam upaya memperoleh pemahaman tentang dimensi lingkungan maka strategi pengambilan responden dengan menggunakan model purposive. Pemilihan sampling dengan model purposive dilakukan dengan judgment sampling.

Indriantoro \& Supomo (2013) menyebutkan bahwa judgment sampling merupakan tipe pemilihan sampel secara tidak acak yang informasinya diperoleh dengan pertimbangan tertentu, maka peneliti menggunakan pengetahuan khusus atau keahlian mereka dengan memilih mana yang diangap mewakili suatu populasi. Responden yang ditentukan melalui teknik purposive ini antara lain: pimpinan(manajer UMKM),karyawan bagian penjualan dan karyawan bagian produksi, konsumen. Berdasar teknik ini diperoleh enam puluh UMKM dengan berbagai jenis usaha. Usaha Konveksi dan handycraft(20), Makanan dan minuman ringan(12), Kuliner(16), jasa bengkel(2), percetakan(2 ), salon kecantikan(6) dan sembako(2).

Variabel penelitian ini meliputi: variabel Lingkungan Internal dan variabel Lingkungan eksternal. Instrument penelitian variabel lingkungan internal dikembangkan berdasar empat perspektif Balance Score Card yaitu: perpesktif keuangan dengan indikator growth(pertumbuhan penjualan); perspektif pelanggan dengan indikator atribut produk, hubungan dengan pelanggan, citra dan reputasi; perpekstif proses bisnis internal dengan indikator inovasi, operasi dan pelayanan purna jual; perpekstif pertumbuhan dan pembelajaran dengan indikator kapabilitas karyawan. Sedangkan variabel lingkungan eksternal dikembangkandariThakkar, Kanda, \&Desmukh,(2008)di ukur dengan indikator SCM(Supply Chain Management) dan CRM(Customer Relationship Management). SCM meliputi : harga pembelian bahan yang kompetitif, kuantitas dan kualitas bahan yang sesuai kebutuhan, ketepatan waktu pengiriman dan penggunaan tehnologi informasi untuk pembelian. Sedangkan 


\section{FAKULTAS EKONOMI DAN BISNIS UNIVERSITAS WIRARAJA - MADURA}

CRM di ukur dengan akuisisi pelanggan.

Semua variabel diukur dengan skala ordinal dari angka1 sampai 5, dimana angka 2 lebih tinggi nilainya daripada angka 1 demikian seterusnya.

Data penelitian dikumpulkan dengan menyebar kuesioner kepada UMKM dan konsumennya di Malang. Selanjutnya dilakukan wawancara kepada pihak terkait yaitu manajemen UMKM, karyawan dan konsumen. Sedangkan analisis data dilakukan dengan pendekatan kuantitatif dan kualitatif. Tahap pertama dilakukan uji validitas data dan pengujian statistik diskriptif. Setelah itu dilakukan analisis faktor untuk menentukan indikator kinerja UMKM berdasar strategi lingkungan. Tahap analisis faktor dimulai dari menyusun matrik korelasi, ekstraksi faktor, rotasi faktor, intepretasi faktor pembuatan factor scores dan mimilih variabel surrogate atau menentukan summated scale. Semua analisis dilakukan dengan software SPPSS.

\section{HASIL PENELITIAN}

Sebelum dilakukan analisis faktor maka dilakukan uji validitas data dengan metode Correlations Spearman's. Dari dua puluh dua(22) pertanyaan maka semua pertanyaan adalah valid sebagaimana hail uji validitas sebagaimana tabel 1 .

Tabel 1

Hasil Ringkasan Uji Validitas

\begin{tabular}{|l|l|l|}
\hline \multicolumn{1}{|c|}{ Item } & \multicolumn{1}{|c|}{ Nilai r } & Keterangan \\
\hline X1.1 & 0,856 & Valid \\
\hline X1.2 & 0,801 & Valid \\
\hline X1.3 & 0,794 & Valid \\
\hline X2.1 & 0,945 & Valid \\
\hline X2.2 & 0,927 & Valid \\
\hline X3.1 & 0,756 & Valid \\
\hline X3.2 & 0,720 & Valid \\
\hline X3.3 & 0,687 & Valid \\
\hline X3.4 & 0,694 & Valid \\
\hline X3.5 & 0,819 & Valid \\
\hline X3.6 & 0,726 & Valid \\
\hline X4.1 & 0,753 & Valid \\
\hline X4.2 & 0,852 & Valid \\
\hline X4.3 & 0,687 & Valid \\
\hline X4.4 & 0,721 & Valid \\
\hline X4.5 & 0,780 & Valid \\
\hline X5.1 & 0,713 & Valid \\
\hline X6.1 & 0,735 & Valid \\
\hline X6.2 & 0,735 & Valid \\
\hline X6.3 & 0,810 & Valid \\
\hline X6.4 & 0,739 & Valid \\
\hline X6.5 & 0,749 & Valid \\
\hline
\end{tabular}


FAKULTAS EKONOMI DAN BISNIS UNIVERSITAS WIRARAJA - MADURA

Berdasar uji korelasi maka dikatakan valid jika nilai $r$ minimal 0,300 sehingga dalam penelitian ini terdapat dua puluh satu item pertanyaan seperti di atas.

Berdasar uji reliabilitas, maka semua variabel penelitian ini adalah reliabel sehingga dapat dilanjutkan untuk pengujian berikutnya. sebagaimana tabel 2.

\section{Analisis Faktor:}

Berikut hasil tahapan dalam hasil ekstraksi Faktor sebagaimana tabel 3 .

Tabel 2

Hasil Uji Reliabilitas

\begin{tabular}{|l|l|l|}
\hline \multicolumn{1}{|c|}{ Variabel } & \multicolumn{1}{c|}{ Cronbach's Alpha } & \multicolumn{1}{c|}{ Keterangan } \\
\hline Keuangan & 0,7400 & Reliabel \\
\hline Bisnis Internal & 0,8543 & Reliabel \\
\hline Pembelajaran & 0,8237 & Reliabel \\
\hline SCM & 0,7381 & Reliabel \\
\hline CRM & 0,6701 & Reliabel \\
\hline Pelanggan & 0,8187 & Reliabel \\
\hline
\end{tabular}

Tabel 3

Hasil Communalities

\begin{tabular}{|l|c|r|}
\hline & Initial & Extraction \\
\hline Keuangan1 & 1,000 &, 759 \\
\hline Keuangan2 & 1,000 &, 849 \\
\hline Keuangan3 & 1,000 &, 870 \\
\hline Bisnis internal & 1,000 &, 785 \\
\hline Bisnis internal & 1,000 &, 610 \\
\hline Pembelajaran1 & 1,000 &, 812 \\
\hline Pembelajaran2 & 1,000 &, 674 \\
\hline Pembelajaran3 & 1,000 &, 529 \\
\hline Pembelajaran4 & 1,000 &, 791 \\
\hline Pembelajaran5 & 1,000 &, 683 \\
\hline Pembelajaran6 & 1,000 &, 599 \\
\hline SCM1 & 1,000 &, 748 \\
\hline SCM2 & 1,000 &, 866 \\
\hline SCM3 & 1,000 &, 854 \\
\hline SCM4 & 1,000 &, 590 \\
\hline CRM1 & 1,000 &, 597 \\
\hline Pelanggan1 & 1,000 &, 683 \\
\hline Pelanggan2 & 1,000 &, 716 \\
\hline Pelanggan3 & 1,000 &, 693 \\
\hline Pelanggan4 & 1,000 &, 643 \\
\hline Pelanggan5 & 1,000 &, 760 \\
\hline Extraction Method: Principal Component Analysis. \\
\hline
\end{tabular}


Tabel 4

Hasil Rotasi Faktor

\begin{tabular}{|l|l|r|r|r|}
\hline \multicolumn{2}{|c|}{ Component } & \multicolumn{3}{|c|}{ Extraction Sums of Squared Loadings } \\
\cline { 3 - 5 } \multicolumn{1}{c|}{} & Total & \% of Variance & Cumulative \% \\
\cline { 2 - 5 } & 1 & 3,999 & 19,045 & 10,045 \\
\cline { 2 - 5 } & 2 & 2,668 & 12,705 & 31,750 \\
\cline { 2 - 5 } & 3 & 2,251 & 10,719 & 42,470 \\
\cline { 2 - 5 } dimension0 & 5 & 1,887 & 8,988 & 51,458 \\
\cline { 2 - 5 } & 6 & 1,767 & 8,416 & 59,874 \\
\cline { 2 - 5 } & 7 & 1,422 & 6,770 & 66,645 \\
\hline
\end{tabular}

Tabel 5

Faktor 1 Sumber Daya

\begin{tabular}{|l|l|}
\hline \multicolumn{1}{|c|}{ Sub faktor } & Nilai ekstrak \\
\hline Bisnis Internal1 & 0,692 \\
\hline Bisnis Internal2 & 0,517 \\
\hline Pembelajaran1 & 0,604 \\
\hline Pembelajaran2 & 0,624 \\
\hline Pembelajaran5 & 0,664 \\
\hline Pembelajaran6 & 0,722 \\
\hline CRM1 & 0,517 \\
\hline
\end{tabular}

Metode untuk melakukan analisis faktor adalah metode extraction. Berdasar metode tersebut maka semua nilai extraction sudah memenuhi kriteria yaitu di atas 0,5. Langkah selanjutnya adalah analisis faktor dengan hasil sebagaimana tabel 4 di atas.

Berdasar tabel 4 di atas, dari dua puluh dua sub faktor mengelompok menjadi tujuh (7) faktor utama. Pada Sub faktor dikatakan menjadi komponen utama faktor jika nilai ekstrak komponen adalah positif dan lebih dari 0,5 . Namun berdasar tabel di atas faktor indikator penetuan kinerja UMKM hanya terdiri dari 4 karena faktor ke-5,6 dan 7 adalah dibentuk oleh sub faktor yang sama. Dengan demikian faktor utama meliputi: faktor sumber daya, faktor keuangan, faktor pelanggan dan faktor Suplly Chain Management (SCM). Berikut tabel faktor utama dan sub faktor pembentuk dengan besaran nilai ekstraknya masing-masing:

Faktor pertama yang membentuk kinerja UMKM adalah faktor Sumber daya. Faktor sumber daya dibentuk oleh sub faktor bisnis internal tentang proses operasional UMKM telah sesuai dengan kualitas yang ditetapkan dan sesuai dengan waktu yang distandarkan. Sebagai dampak dari hal ini dapat menurunkan biaya dan dapat mencapai penjulan yang ditargetkan. Sebagaimana diketahui bahwa penjualan rata-rata UMKM sebesar Rp.55.279.344,- per bulan.

Sub faktor berikutnya tentang sumber daya adalah bahwa UMKM telah memberikan pelatihan secara 
berkala kepada karyawan. Hal ini juga telah didukung dengan anggaran kebutuhan pelatihan karyawan. Secara umum UMKM telah mengikutsertakan karyawan dalam pelatihan rata-rata 12(dua belas) kali dalam tahun 2018. Pelatihan kepada karyawan merupakan salah satu upaya untuk meningkatkan kinerja karyawan. Biaya pelatihan yang disediakan oleh UMKM dapat menjadi penentu kinerja UMKM secara lebih luas. Pelatihan atau training dilakukan berkaitan dengan peningkatan kemampuan administrasi akuntansi, pembuatan kemasan produk, dan pemasaran produk. Training dilakukan dengan mengikutkan karyawan pada Dinas Koperasi dan UMKM Malang, dan Dinas PLUT Batu.

Selanjutnya subfaktor yang membentuk faktor sumber daya adalah proses pembelajaran berkaitan dengan kenyamanan karyawan dalam bekerja. Kenyamanan karyawan dalam bekerja ini berdampak positif pada kenaikan jenis produk dibanding tahun sebelumnya. Karyawan merasa aman dengan cara melakukan pekerjaan di rumahnya masing-masing. Sebagai contoh karyawan UMKM Konveksi Rosa membawa bahan kain selanjutnya melakukan proses bordir di rumah masing-masing. Demikian juga banyak UMKM yang bergerak bidang produksi makanan dan minuman berbahan apel memperbolehkan karyawan untuk mengupas apel di rumahnya masingmasing. Rata-rata karyawan pada UMKM adalah sejumlah tujuh(7) orang. Dengan jumlah karyawan yang relatif sedikit maka UMKM dapat dengan mudah mengawasi pekerjaan karyawannya.

$\begin{array}{lrr}\text { Faktor } & \text { hubungan } & \text { dengan } \\ \text { pelanggan } & \text { atau dikenal dengan } \\ \text { Customer } & \text { Relationship }\end{array}$

Management(CRM) juga merupakan sub faktor sumber daya. CRM dapat dilakukan dengan melakukan akuisisi atau memperoleh pelanggan baru. Sebagaimana hasil penelitian ini menunjukkan bahwa pada tahun 2018 UMKM memiliki rata-rata jumlah pelanggan 672 orang sebagai akibat meningkatnya jumlah pelanggan tahun 2018 dibanding tahun sebelumnya. Akuisisi pelanggan baru tampak pada perluasan wilayah pemasarannya. Pada tahun 2018 ini wilayah pemasaran UMKM telah meningkat pada beberapa kota di Jawa Timur seperti Surabaya, bahkan ada yang ke Jakarta dan Bali. Jika dikategorikan berdasar jumlah karyawan UMKM di Malang dapat dikategorikan yang memiliki karyawan kurang 5 orang sejumlah 48,33\%, memiliki karyawan antara 5 orang sampai $\quad 10 \quad$ orang sejumlah 26,67\%,memiliki karyawan 10 orang sampai 15 orang sejumlah $16,67 \%$ dan 


\section{FAKULTAS EKONOMI DAN BISNIS UNIVERSITAS WIRARAJA - MADURA}

sisanya 8,33\% memiliki karyawan lebih dari 10 orang sampai 20 orang.

Sub faktor ke-3 adalah kenaikan jumlah pelanggan. Karyawan yang sudah diberikan pendidikan, pelatihan dan reward yang sesuai maka akan berdampak pada produktivitas karyawan. Reward merupakan cara untuk maksimalisasi kinerja karyawan. Kinerja karyawan dapat dimaksimalisasi dengan beberapa cara yaitu: penyediaan meaningful work, recognition, reward dan schedule kerja yang baik(Allen \& Meyer,2006).Reward dapat berupa financial seperti gaji dan bonus, namun bisa juga berupa promosi pada jabatan yang lebih tinggi, pekerjaan dengan keahlian tertentu atau spesifik.Sehingga produk yang dihasilkan semakin berkualitas yang pada akhirnya berdampak pada kenaikan jumlah penjualan dan jumlah pelanggan, meskipun rata-rata kenaikan jumlah penjualan dan pelanggan hanya $5 \%$ pada tahun 2018.

Indikator kinerja UMKM dapat diukur dengan faktor keuangan. Faktor keuangan terdiri dari sub faktor jumlah penjualan. Jumlah penjualan UMKM tahun 2018 berfluktuasi ada yang naik atau turun, bahkan ada yang stabil dibanding tahun sebelumnya. Sebagaimana berdasar data diketahui bahwa rata-rata penjulaan per bulan UMKM pada tahun 2018 sebesar 53.279.344,- dan rata-rata laba sebesar Rp. 15.349.180,- per bulan seperti tampak pada tabel 7 .

Tabel 6

Faktor 2: Keuangan

\begin{tabular}{|l|l|}
\hline Sub faktor & Nilai Ekstrak \\
\hline Keuangan 2 & 0,766 \\
\hline Keuangan 3 & 0.520 \\
\hline
\end{tabular}

Tabel 7

Kalsifikasi UMKM berdasar Nilai Penjualan

\begin{tabular}{|c|c|c|}
\hline Nilai Penjualan & Jumlah & Presentase \\
\hline$<50$ juta & 43 & $71.66 \%$ \\
\hline $50-250$ juta & 15 & $25 \%$ \\
\hline$<250-500$ juta & 1 & $1.67 \%$ \\
\hline$>500$ juta & 1 & $1.67 \%$ \\
\hline Total & 60 & $100 \%$ \\
\hline
\end{tabular}

Tabel 8

Faktor 3: Pelanggan

\begin{tabular}{|l|l|}
\hline Sub faktor & Nilai Ekstrak \\
\hline Pelanggan 2 & 0,602 \\
\hline Pelanggan 3 & 0,668 \\
\hline Pelanggan 4 & 0,537 \\
\hline Pelanggan 5 & 0,672 \\
\hline
\end{tabular}


Penjualan UMKM pada tahun 2018 tergolong rendah. Hal ini dapat dilihat tabel di atas menunjukkan tujuh puluh satu koma enam enam persen UMKM menghasilkan penjulan sebesar Rp. 50 juta dan sisanya menghasilkan penjualan lebih dari Rp.50 juta sampai Rp.500 juta.

Faktor pelanggan menjadi indikator utama dalam menentukan kinerja UMKM. Faktor Pelanggan dibentuk dari sub faktor pelanggan yang meliputi: strategi mencari pelanggan baru serta respon yang cepat oleh UMKM dalam menanggapi keluhan pelanggan. Selain itu faktor pelanggan juga ditentukan oleh peningkatan jumlah produk dan peningkatan pelayanan kepada pelanggan.

Selama ini UMKM melakukan stategi promosi dan iklan untuk mencari pelanggan baru. UMKM telah memanfaatkan tehnologi informasi untuk mencari pelanggan baru berupa iklan maupun diskon dengan mengunakan media sosial seperti FB, What application dan Instagram sehingga dapat menangani data dengan jumlah dan frekuensi yang besar. Mesipun wilayah pemasaran UMKM masih terbatas di kota dan kabupaten Malang saja yaitu sebesar tujuh puluh tiga koma tiga tiga persen $(73,33 \%)$ dan sisanya wilayah pemasaran kota dan kabupaten di Jawa Timur (21,68\%),
Bali(3,33\%) dan Jakarta/ Jawa

Barat $(1,66 \%)$.

Jika diamati dari jumlah pelanggan maka empat puluh tiga koma tiga-tiga persen(43,33\%) UMKM memiliki jumlah pelanggan diantara 100 orang sampai 500 orang. Dan tiga puluh koma nol satu persen(30.01\%) memiliki jumlah pelanggan lebih dari lima ratus orang, dan sisanya UMKM memiliki jumlah pelanggan dibawah seratus orang $(26,66 \%)$ Dengan demikian dilihat dari jumlah pelanggan maka UMKM tersebut termasuk UMKM yang memiliki jumlah pelanggan cukup besar.

Jumlah pelanggan yang cukup besar ini sudah diimbangi dengan kualitas layanan yang baik. Dengan jumlah pelanggan 41.041 orang dan jumlah keluhan dari pelanggan hanya sembilan belas(19) orang maka keluhan pelanggan relatif kecil karena hanya $2,8 \%$ dari total pelanggan. Dengan demikian dapat dikatakan bahwa UMKM telah responsif terhadap keluhan pelanggan. Berdasar data dari enam puluh UMKM, hanya $10 \%$ UMKM yang tidak melakukan peningkatan pelayanan kepada pelanggan dari tahun sebelumnya, dan sisanya telah melakukan perbaikan dan peningkatan pelayanan kepada pelanggan. 
Faktor 4: SCM (Supply Chain Management)

Kinerja UMKM ditentukan oleh faktor hubungan dengan pemasok atau dikenal Supply Chain Management(CSM). Berikut hasil subfaktor yang membentuk faktor SCM sebagaimana tabel 9.

Kinerja UMKM dapat diukur dengan bagaimana UMKM memiliki hubungan dengan pemasok atau dikenal Supply Chain Management(SCM). Sub faktor SCM terdiri dari faktor pemenuhan kebutuhan kuantitas pembelian bahan baku, kualitas bahan baku yang baik dan pengiriman bahan yang tepat waktu.

Pemasok bahan dan barang lainnya diperoleh UMKMM dari lokal yaitu dari Kota Malang, Kota Batu dan Kabupaten Malang(75,37\%) dan sisanya dari daerah sekitar seperti Pasuruan. Kualitas bahan dan barang yang diterima dari pemasok telah memiliki kualitas yang baik sesuai yang distandarkan oleh UMKM. Pembelian bahan dilakukan UMKM cukup sering yaitu dua(2) hari sekali. Transportasi pengiriman bahan yang digunakan berupa mobil pribadi, jasa pengiriman lain seperti JNE dan cargo yang lain.

Dengan demikian faktor SCM pada UMKM dapat dikatakan sudah baik karena kebutuhan bahan telah dapat dipenuhi oleh pemasok dengan jumlah dan kualitas bahan yang baik serta barang yang dibeli dapat diterima tepat waktu.

Hasil penelitian ini sesuai dengan penelitian yang dilakukan di India oleh Kumar, Singh, \& Shankar(2015) terkait faktor sukses untuk dalam penerapan SCM pada UKM di India dan dampaknya terhadap kinerja. Hasil penelitian memberi rekomendasi untuk mengembangkan strategi supply chain secara efektif setelah menganalisis lingkungan bisnis dan rencana jangka panjang. Dengan demikian indikator penentuan penilaian kinerja penerapan faktor lingkungan supply chain management UMKM meliputi: faktor sumber daya, faktor keuangan, faktor pelangggan dan faktor SCM(Supply Chain Management).

Tabel 9

Faktor SCM

\begin{tabular}{|l|l|}
\hline Sub fakor & Nilai Ekstrak \\
\hline SCM 2 & 0,595 \\
\hline SCM 3 & 0,631 \\
\hline SCM 4 & 0,528 \\
\hline
\end{tabular}


Penentuan kinerja UMKM dapat ditentukan dari faktor sumber daya. Sumber daya secara umum terdiri dari Man, material, money, machine, method. Sebagaimana pada UMKM ini memiliki rata-rata jumlah tenaga kerja(man) sebesar tujuh(7) orang. Dengan penyediaan dana(money) pelatihan karyawan terbukti karyawan dapat meningkatkan produktivitasnya sehingga jenis produk meningkat dibanding tahun sebelumnya. Disamping itu UMKM telah memiliki sumber daya method dalam memproses produksinya dalam bentuk penjadwalan proses produksi dan anggaran biaya produksi meskipun masih sederhana. Pendajwalan proses dan anggaran biaya produksi ditentukan berdasar perkiraan saja belum mendasarkan pada informasi lain seperti proyeksi produksi.

Dalam penelitian ini terbukti bahwa sub faktor sumber daya berupa karyawan(man), machine dan method memerlukan kegiatan pelatihan karyawan. Pelatihan(training) dan development merupakan hal kompleks bagi perusahaan yang pada masa pertumbuhan(growth). Sebagaimana UMKM di Malang yang sedang mengalami masa growth maka harus memperhatikan aktivitas pendidikan dan development. Seperti dapat dilihat pada data di atas bahwa UMKM yang memiliki karyawan kurang dari lima orang sebanyak 48,33\% hal ini menunjukkan UMKM yang baru berdiri dan pada tahap pertumbuhan. Berkaitan dengan pengembangan karyawan maka perlu dilakukan beberapa tahap mulai identifikasi kebutuhan progrmam, desain program, implementasi dan evaluasi program pengembangan untuk karyawanseperti disebutkan Allen \& Meyer(2006). Hal ini membuktikan bahwa faktor pelatihan karyawan merupakan indikator kinerja UMKM. Seperti temuan Ahmedova(2015)bahwa human capital merupakan faktor penentu keunggulan UMKM di Bulgaria. Demikian juga temuan penelitian tentang pengembangan karyawan oleh Semrau, Ambos, \& Kraus (2016) menunjukkan bahwa terdapat hubungan entrepreneur orientation karyawan dengan performance SME pada berbagai negara yaitu: US, Netherland, China, Malaysia, India, Germany dan Spain.

$$
\text { Selanjutnya kinerja }
$$
karyawan(man) juga ditentukan oleh faslistas karyawan . Untuk itu merupakan hal yang harus diperhatikan manajer untuk mencapai kinerja UMKM. Hal ini menjadi salah satu sebab karyawan betah dan merasa nyaman bekerja di rumahnya. Sesuai teori motivasi Maslow bahwa kebutuhan manusia tersusun dari hirarki yang paling rendah sampai yang paling tinggi. 
Motivasi dari yang paling rendah ke yang paling tinggi meliputi: kebutuhan fisiologis, kebutuhan keamanan dan keselamatan kerja, kebutuhan sosial, kebutuhan penghargaan dan kebutuhan aktualisasi. Nampak bahwa karyawan UMKM di Malang menunjukkan motivasi pada tingkatan keamanan dan keselamatan kerja, bahwa karyawan lebih nyaman jika bekerja di rumahnya masing-masing. Hal ini diperkuat oleh temuan penelitian Paulraj, Chen, \& Blome, (2017) pada perusahaan di Jerman bahwa motivasi moral dan motivasi relationalberpengaruh signifikan pada keberlanjutan Supply Chain Management(SSCM). Dan selanjutnya SSCM berpengaruh pada kinerja keuangan dan enviroment performance. Hal ini membuktikan bahwa fasilitas untuk karyawan dapat menjadi indikator penilaian kinerja UMKM.

Fasilitas karyawan dapat merupakan workplace flexibility yaitu fasilitas yang lebih fleksible dengan perkembangan tehnologi. Seperti halnya karyawan bagian pemasaran tidah harus datang setiap hari pada UMKM namun dapat melakukan pekerjaannya dengan model telecommuting. Telecommuting adalah perjanjian kerja di mana karyawan memperoleh fleksibilitas bekerja dalam hal tempat,dan waktu kerja dengan bantuan tehnologi informasi. Dengan telecommuting maka waktu kerja juga lebih fleksible(flextime) namun tetap efektif untuk mencapai tujuan dan target karyawan dapat tercapai. Disamping itu, fasilitas karyawan berupa tempat tinggal untuk keluarga(family leave) juga harus menjadi fokus bagi manajer. (Allen \& Meyer,2006 hal: 394)

Berkaitan dengan method dapat meliputi tehnik, cara atau iklim dalam sebuah perusahaan yang mempengaruhi UMKM dalam mencapai tujuan dan hasilnya. Iklim organisasi UMKM sangat mempengaruhi kinerja, sebagaimana penelitian (Nugraha, Susilo, \& Aini, 2018) pada industry adverting di Malang menemukan bahwa iklim organisasi berpengaruh pada kinerja non finansial.

Indikator kinerja UMKM dapat diukur dengan faktor keuangan. Faktor keuangan merupakan hasil dari proses perolehan pelanggan, produk yang berkualitas, sumber daya dan fasilitas serta proses perolehan bahan(supply chain management). Sebagaimana temuan Subhan \& Putro( 2017) bahwa supply chain management(SCM) berpengaruh pada kinerja keuangan.

Faktor ke-4 indikator kinerja UMKM dapat ditentukan berdasar faktor pelanggan. UMKM di Malang telah melakukan strategi promosi dan iklan untuk mencari pelanggan baru. UMKM 
telah memanfaatkan tehnologi informasi untuk mencari pelanggan baru berupa iklan maupun diskon dengan mengunakan media sosial seperti FB, What application dan Instagram sehingga dapat menangani data dengan jumlah dan frekuensi yang besar . Hasil penelitian ini diperkuat temuanCheong(2011) bahwa penggunaan tehnologi infomasi merupakan solusi untuk melakukan adopsi supply chain management UMKM. Demikian juga hasil penelitian Keen, Wetzels, de Ruyter, \& Feinberg, (2004)bahwa keputusan pelanggan dalam membeli produk ritel ditentukan oleh store, catalog or internet dan product price.

Dapat diamati lebih jauh bahwa rata-rata jumlah pelanggan pada tahun 2018 pada UMKM di Malang adalah sebanyak 672 orang, sedangkan rata-rata keluhan pelanggan setiap bulan dapat dikatakan sedikit karena hanya 2,8\% dari total pelanggan.

Hal ini tidak lepas dari upaya UMKM dalam menjalankan proses operasional sesuai dengan standar kualitas yang telah ditetapkan dan biaya yang ditetapkan sehingga semua biaya yang di keluarkan telah efisien dan efektif sesuai tujuan yang telah ditentukan. Terbukti biaya yang dikeluarkan dapat ditekan karena semua pekerjaan sesuai jadwal yang telah dibuat sebelumnya. Sebagaimana penelitian Hadiati \& Ruci(1999) tentang Analisis kinerja kualitas pelayanan terhadap kepuasan pelanggan Telkomsel Malang Area. Penelitian tersebut menemukan bahwa tanggapan keluahan pelanggan dapat diidentifikasi untuk menilai mutu kinerja jasa kepuasan pelanggan.

Faktor penilaian kinerja UMKM dapat diukur dari faktor hubungan UMKM dengan pemasok atau dikenal dengan Supply Chain Management. Penelitianyang dilakukan Paulraj, Chen, \& Blome (2017)pada 1.400 perusahaan di Jerman, menemukan bahwa: Supply Chain Management(SCM) berpengaruh pada kinerja keuangan dan enviroment performance.Demikian juga temuan Tower \& Burnes,(2008) tentang supply chain management dan perencanaan usaha untuk UKM, ditemukan bahwa salah satu faktor penerapan Suplly chain management SME adalah elemen aktivitas berkaitan dengan efektivitas hubungan perdagangan baik dengan pelanggan maupun dengan pemasok. Dengan demikian hubungan dengan pemasok dapat menjadi faktor penentu penilaian kinerja UMKM.

Hasil penelitian Li, Huang, Yu, \& Zhao, (2011) tentang UKM menemukan bahwa untuk membangun sustainabilitas dan operasional yang efektif pada UKM di China dengan menggunakan supply 
chain management. Li et.al(2011) menggunakan restrained-scale dan capital-deficiency tetapi pada waktu yang bersamaan melakukan inovasi untuk mencapai integrasi antar supply chain partner, arus kas yang lebih efisien, mempercepat pertumbuhan, dan menjaga keuntungan jangka panjang. Demikian juga tentang explorasi strategi UMKM di Italia telah dilakukan olehKöhr, Camanzi, \& Malorgio,(2018) dan menemukan bahwa faktor yang mempegaruhi strategi UMKM adalah diversifikasi internasional dan scope geografi.

Penelitian tentang Rantai Pasokan untuk UMKM pangan di Malang telah dilakukan oleh Latifah (2016). Hasil penelitian menunjukkan bahwa rantai pasokan UMKM pangan di Malang dipengaruhi oleh pelaku ekonomi yang terdiri dari petani, produsen UMKM pangan dan konsumen. Jika diamati dari ketersediaan bahan baku apel, ternyata hasil panen petani belum dapat memenuhi jumlah kebutuhan . Demikian juga harga jual apel juga termasuk rendah dibanding harga pasarnya. Jika ditinjau dari preferensi konsumennya, maka sebenarnya konsumen produk pangan olahan apel ini tergolong rendah. Konsumen hanya membeli produk berdasar kualitas barang dan belum mempertimbangkan faktor lain seperti harga, lokasi, store desain dan visual produk sebagaimana faktor ini justru akan menjadi penentu loyalitas pelanggan.

Demikian juga kajian tentang faktor-faktor yang mempengaruhi rantai pasokan UMKM yang memproduksi makanan dan minuman berbahan apel di Malang dapat diketahui bahwa faktor perencanaan penjualan, penjadwalan produksi, transportasi pembelian bahan baku dan transportasi penjualan barang dagang tidak mempengaruhi rantai pasokan UMKM, namun faktor lingkungan mempengaruhi rantai pasokan UMKM (Latifah, 2017). Faktor lingkungan meliputi: inovasi, intelectual knowledge, best practice, internationalisation UMKM dan kebijakan ekonomi terbukti berpengaruh signifikan terhadap Rantai Nilai UMKM. Sebagiamana hasil penelitian Tower \& Burnes (2008)tentang supply chain management dan perencanaan usaha untuk UKM. Dikemukakan bahwa supply chain manajemen UKM terdiri dari tiga elemen yaitu: (1) elemen aktivitas UKM yang mempengaruhi efektivitas hubungan perdagangan; (2) elemen yang mempengaruhi efektivitas sistem pengendalian aktivitas produksi UKM; (3) strategi dan kebutuhan operasional UKM yang berkaitan dengan dua elemen sebelumnya. 
FAKULTAS EKONOMI DAN BISNIS UNIVERSITAS WIRARAJA - MADURA

KESIMPULAN DAN SARAN

Berdasarkan analisis data pada UMKM di Malang tentang faktor penentuan indikator kinerja UMKM, maka dapat dikatakan terdapat empat (4) faktor untuk mengukur kinerja UMKM. Yaitu faktor sumber daya, faktor keuangan, faktor faktor pelanggan dan $\mathrm{SCM}$ (Supply Chain Management). Faktor pertama yaitu sumber daya yang meliputi sub faktor proses operasional, pelatihan karyawan, kenyamanan karyawan dalam bekerja dan hubungan perusahaan dengan konsumen atau Customer Relationship

Management(CRM). Sedangkana faktor kedua adalah keuangan yang dibentuk oleh sub faktor penjualan. Faktor ketiga adalah pelanggan yang dibentuk sub faktor upaya-upaya khusus untuk mempertahankan pelanggan dan cara UMKM dalam menarik pelanggan melalui promosi dan iklan serta responsif terhadap keluhan pelanggan. Dan faktor ke empat adalah hubungan UMKM dengan pemasok atau yang disebut sebagai SCM(Supply Chain Management). Berdasarkan hasil penelitian pada UMKM di Malang dapat dikatakan bahwa SCM sudah bagus terbukti pengiriman bahan yang tepat waktu dan sudah menggunakan media internet untuk melakukan pembelian bahan.

$$
\text { Penelitian ini memiliki }
$$

keterbatasan diantaranya adalah ketersediaan data dari UMKM tentang catatan keuangan dan administrasi yang tidak lengkap, serta kesulitan dalam pengelompokkan UMKM yang sejenis. Untuk itu saran bagi peneliti selanjutnya dapat menggunakan obyek UMKM dengan skala yang lebih besar. Saran bagi manajer UMKM hendaknya dapat menggunakan informasi keuangan, pelanggan, karyawan dan pemasok sebagai pertimbangan menentukan strategi mencapai kinerja yang lebih baik.

\section{DAFTAR PUSTAKA}

Ahmedova, S. (2015). Factors for Increasing the competitiveness of SME in Bulgaria. Science Direct: Procedia-Social and Behavioral Science, 195.

Hadiati, S., \& Ruci, S. (1999). Analisis KInerja Kualitas Pelayanan Terhadap Kepuasan Pelanggan Pada Telkomsel Malang Area. Jurnal Manajemen dan Kewirausahaan FEB UNiv.Petra, l(1), 56-64. https://doi.org/10.9744

Indriantoro, N., \& Supomo, B. (2013). Metode Penelitian Bisnis untuk Akuntansi dan Manajemen. BPFE Yogyakarta.

Keen, C., Wetzels, M., de Ruyter, K., \& Feinberg, R. (2004). E-tailers versus retailers. Journal of Business Research, 57(7), 685-695. https://doi.org/10.1016/S01482963(02)00360-0

Köhr, C. K., Camanzi, L., \& Malorgio, G. (2018). Exploring structural and strategic correlates of difficulties in the internationalisation process of Italian wine SMEs. Wine Economics 
and Policy, 7(1), 13-23. https://doi.org/10.1016/j.wep.2018.0 1.004

Latifah, S. W. (2017). Analisis Faktorfaktor yang Mempengaruhi Rantai Pasokan UMKM Berbasis Apel Di Malang. Universitas Muhammadiyah Malang: Prosiding Senaspro 2.

Latifah, S. W., \& Yuliati, U. (2019). Dimensi Kompetitif Lingkungan Rantai Pasokan Upaya Mencapai Keunggulan Bersaing UMKM Di Malang. Jurnal Benefit Manajemen dan Bisnis Universitas Muhammadiyah Surakarta, 4(1), 41-53.

Li, Y., Huang Y, J, Y., \& Zhao C. (2011). Operation Mode of Small and Medium-sized Commercial Entreprises at Western Area China Based on Supply Chain. Procedia Enginering, 15, 1405-1409. https://doi.org/10.1016

Mcleod, R., \& Schell, G. (2008). Management Information System. Pearson Education Inc New Jersey.

Nugraha, P. C., Susilo, H., \& Aini, E. K. (2018). PENGARUH HUMAN CAPITAL TERHADAP KINERJA PERUSAHAAN. Jurnal Administrasi Bisnis, 57(2), 180-189.

Paulraj, A., Chen, I. J., \& Blome, C. (2017). Motives and Performance Outcomes of Sustainable Supply Chain Management Practices: A Multi-theoretical Perspective. Journal of Business Ethics, 145(2), 239-258.

https://doi.org/10.1007/s10551-0152857-0

R.Allen, K., \& Earl C.Meyer. (2006). Entrepreneurship \& Small Business Management. Glencoe/McGraw-Hill.

R.Kumar, Singh, R. K., \& Shankar, R. (2015). Critical success factors for implementation of supply chain management in Indian small and medium enterprises and their impact on performance. IIMB Management
Review ScienceDirect., 27(2), 92104.

Semrau, T., Ambos, T., \& Sascha Kraus. (2016). Entrepreneurial orientation and SME performance across societal cultures: An international study. Journal of Business Research, 69(5), 1928-1932.

https://doi.org/10.1016/j.jbusres.2015 .10 .082

(Shawn) Jang SooCheong. (2011). Hospitality finance research during recent two decades. International Journal of Contemporary Hospitality Management, 23(4), 479-497. https://doi.org/10.1108/09596111111 129995

Latifah,SW. (2016). Karakteristik Pelaku Ekonomi Penunjang Supply Chain Management UKM Pangan di Malang. Proceding Seminar Nasional Universitas Tarumanegara.

Subhan, A., \& Putro, B. E. (2017). Supply Chain and Quality Management Practice: Its Impact on Competitive Advantage and Firm Performance (Study on Small and Medium Enterprises at West Java). Jurnal Manajemen Teknologi, ITB, 16(3), 222-240. https://doi.org//10.12695/jmt.2017.16 3.1

Thakkar, J., Kanda, A., \& S.G.Desmukh. (2008). Supply Chain Management in SMEs: Development of constructs and proporsitions. Asia Pasific Journal of Marketing and Logistics, 20(1), 97-131.

Tower, N., \& Burnes, B. (2008). A Commposite Framework of Supply Chain Management and Enterprise Planning for Small and Medium Sized Manufacturing Enterorises. Supply Chain management An International Journal, 13(5), 349355. https://doi.org/10.1108

\begin{tabular}{|c|c|}
\hline $\begin{array}{c}\text { Zaroni. }(2018) . \\
\text { Perusahaan. }\end{array}$ & $\begin{array}{l}\text { Menilai } \\
\text { Supply }\end{array}$ \\
\hline
\end{tabular}

